\title{
The role of nitric oxide in apoptosis modulation in newborns with pneumonia
}

\author{
PAVLYSHYN HALYNA, SARAPUK IRYNA \\ Department of pediatrics 2, Ternopil State Medical University named by I.Ya. Horbachevsky, Ternopil, Ukraine \\ Corresponding author: \\ Iryna Sarapuk \\ Department of pediatrics 2 \\ Ternopil State Medical University named by I.Ya. Horbachevsky \\ 41/14, Lomonosov str., Ternopil, Ukraine \\ Phone: +380502081147 \\ E-mail:prostoirusya@ukr.net
}

\section{ABSTRACT}

Introduction. Nitric oxide (NO) is an important diagnostic marker and mediator in the inflammatory process, which plays a key role in the mechanism of programmed cell death, thus, forming the basis of many pathological diseases.

Methods. The study involved 73 newborns with pneumonia (moderate severity in 44 neonates (group 1), severe pneumonia in 29 (group 2)). The intensity of neutrophil apoptosis and necrosis was determined by flow cytometry, whereas nitric oxide metabolites were measured by spectrophotometry.

Results. The level of nitric oxide metabolites $(\mathrm{NO} 2+\mathrm{NO} 3)$ in newborns with pneumonia was higher than in healthy children (16.93 $(15.82 ; 17.79) \mu \mathrm{mol} / \mathrm{ml})$ and correlated with disease severity (in group 1 - $22.65(21.42 ; 23.40) \mu \mathrm{mol} / \mathrm{ml}$ in group 2 - $26.82(25.81 ; 27.91) \mu \mathrm{mol} / \mathrm{ml})$. The level of NO3 increased moderately, while $\mathrm{NO} 2$ generation was more intense, exceeding control indexes in both groups (pc$1<0.001$; pc- $2<0.001$; p $1-2<0.001$ ).

The occurrence of intensive neutrophil apoptosis was revealed in newborns with pneumonia of moderate severity (pc$1<0.001)$, while necrosis prevailed in severe pneumonia $(\mathrm{pc}-2<0.001)$.

Inverse correlation $(\mathrm{R}=-0.63 ; \mathrm{p}<0.05)$ was found between the level of nitric oxide metabolites and neutrophil apoptosis; and direct correlation $(\mathrm{R}=0.68 ; \mathrm{p}<0.05)$ was revealed between $\mathrm{NO}$ metabolites and neutrophil necrosis indices.

Conclusions. Increased generation of nitric oxide metabolites, that directly correlated with disease severity in newborns with pneumonia, was found. NO2 has multidirectional effects on neutrophil apoptosis and necrosis, leading to toxic accumulation of neutrophils in the organism, thus enhancing the inflammatory and intoxication process that impact disease severity.

Key words: nitric oxide, apoptosis, necrosis, neutrophils, pneumonia, newborn

\section{INTRODUCTION}

Nitric oxide (NO) is a signaling molecule that plays a key role in the pathogenesis of inflammation. It is normally synthesized by many cell types involved in immunity and inflammation and it regulates the functional activity, growth and death of many immune and inflammatory cells including macrophages, $\mathrm{T}$ lymphocytes, antigen-presenting cells, mast cells, neutrophils and natural killer cells. (1-3) It also promotes an anti-inflammatory effect under normal physiological conditions, however, in abnormal situations, $\mathrm{NO}$ is considered a pro-inflammatory mediator that induces inflammation due to its over production. (4)

Nitric oxide hyperproduction induced by NO-synthase is stimulated during viral and bacterial infection through proinflammatory cytokines ( $\gamma$-interferon, tumor necrosis factor alpha or IL-1). This production of nitric oxide in phagocytic cells causes the death of various pathogens and stops their growth. The antimicrobial action of nitric oxide is manifested by the ability of the reactive intermediate products of its metabolism to cause nitrosylation and deamination of proteins, oxidative damage and breach of the DNA repair system, blocking some of their enzymes. Also NO influences infectious agent's apoptotic cell death, thus limiting a favorable environment for reproduction of microorganisms and infectious dissemination. At the same time, NO-synthase controls the biosynthesis of IL-4, IL-11, IL-13, which are inhibi- tors of the inflammatory response. (5) It is known that $\mathrm{NO}$ is involved in nonspecific immunity mechanisms not only through the modulation of inflammation, but also through the modulation of apoptosis. Diametrically opposite effects of NO on programmed cell death are described. The NO multidirectional effect is manifested in its ability, on the one hand, to protect cells from apoptotic signals, on the other - to cause this process. (6)

Nitric oxide influence on inflammation and programmed cell death continues to be studied. There is an unknown relationship between NO and apoptosis of effector blood cells in newborns with an inflammatory process of the lungs.

\section{METHODS}

The study involved 73 newborns with pneumonia, who were treated in Ternopil Regional Children's Clinical Hospital. All infants underwent complex clinical, laboratory and instrumental investigation according to national guidelines. (7)

Children were divided into 2 groups according to the degree of clinical and laboratory signs. The first group (Gr. 1) included $44((60.3 \pm 5.8) \%)$ children with pneumonia of moderate severity, whereas the second group (Gr. 2) had 29 ((39.7 \pm $5.8) \%)$ children with severe pneumonia. The control group included 23 healthy newborns.

The percentage of neutrophils that were in a state of apoptosis and necrosis was determined in peripheral blood. Neutrophilic granulocytes were isolated using two different gradients of Ficoll-Paque $(1.077 \mathrm{~g} /$ $\mathrm{cm} 3)$ and Ficoll-Urografin $(1.095 \mathrm{~g} / \mathrm{cm} 3)$ by the method of M. Looney, M. Matthay (2009). (8) Cells were analyzed by flow cytometry using an EPICS XL flow cytom- 
eter («Beckman Coulter», USA). The activity of caspase-3 was determined by spectrophotometry (M. Bonomini, S. Dottori, A. Amoroso, 2004). (9)

The level of NO metabolites (nitrites and nitrates) in the serum was determined using spectrophotometry (M. Brabcova, 2003). (10)

Statistical analyses were performed using Excell for Windows and Statistica 7.0. for Windows. We used Nonparametric Univariate Statistics for Quantitative Variables: Median (Me) and Interquartile Range (Lq - lower quartile; Uq - upper quartile) for samples with non-Gaussian distribution. Non parametric Mann Whitney U test (MW) was used for comparison between 2 groups. Kruskal-Wallis one-way analysis of variance was used for comparison more than 2 groups; the level of statistical significance according to the Bonferroni amendment was elected as $\mathrm{p}<0.025$ for comparison of indicators with the control group. Level of discrimination was determined using Discriminant Function Analysis with Wilks' lambda and $\mathrm{F}$ to enter a value for variable computing.

\section{RESULTS}

Nitric oxide is rapidly oxidized to its final stable metabolites (nitrites and nitrates), which are indirect markers of its concentration in the organism. Levels of nitrites and nitrates in the blood were significantly increased in neonates with pneumonia compared to the control group (figure 1). Thus, the total content of nitric oxide metabolites (NO2-+ NO3-) was 23.86 $(22.35 ; 25.96) \mu \mathrm{mol} / \mathrm{ml}$, while in the control group it was $16.93(15.82 ; 17.79) \mu \mathrm{mol} /$ $\mathrm{ml}(\mathrm{p}<0.001)$. The total content of NO metabolites increased by 1.4 times, nitrate (NO3) by 1.3 times, while the level of nitrites (NO2-) increases by 4.5 times. The percentage of NO2- exceeded the control indexes by 3.1 times and was 14.49 (13.56; 15.40) \%.

The level of nitric oxide metabolites (NO2- + NO3) depended on disease severity (tables 1,2). The concentration of NO3 increased moderately, exceeding the control indicators by 1.22 times in Group 1 patients and 1.4 times in the second group (pc-1<0.001; pc-2<0.001). NO2- formation in the examined children was more intense. In particular, this stable metabolite increased 4.08 times in the first group and in 5.61 times in the second group, compared with children in the control group (pc- $1<0.001$, pc- $2<0.001$ ). Significant differences in NO2- concentration were determined using pairwise comparison between groups ( $1-2<0.001)$.

The investigation of neutrophil apoptosis and necrosis intensity and the activity of caspase- 3 was carried out in the examined newborns. The growth of neutrophil apoptosis was found in newborns with pneumonia compared to healthy ones ( $\mathrm{p}$ $<0.001$ ). The intensity of apoptosis was dependent on disease severity (figure 2). Thus, increased intensity of neutrophil apoptosis - $17.87(16.50 ; 18.86) \%$ was found in children in Group 1 compared to healthy newborns $(7.12(6.27 ; 8.53) \%)$, pc- $1<0.001$. Newborns in Group 2 also

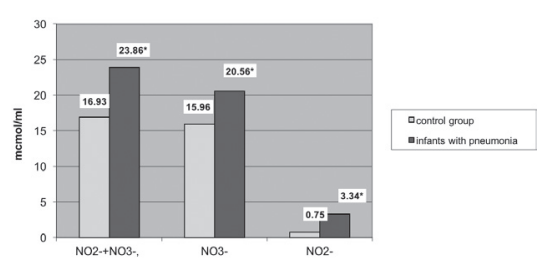

Figure 1. Concentration of nitric oxide (NO) metabolites in infants with pneumonia.

had elevated levels of neutrophil apoptosis $(11.43(10.60 ; 13.61) \%)$ compared to the control group ( $\mathrm{pc}-2<0.001)$, but these indicators were lower in comparison with Group 1. Significant differences were determined using pairwise comparison between groups ( $\mathrm{p} 1-2<0.001)$.

Apoptotic cell death is associated with cascade activation of the apoptotic protease caspases. Caspase- 3 is one of the effector caspases, which play a major role in the activation of programmed cell death. Increased activity of this caspase was found in newborns with pneumonia (24.62 $(18.21 ; 28.15) \mathrm{pmol} / \mathrm{mg}$ protein) compared to the control group $(3.47(3.05 ; 3.96)$ $\mathrm{pmol} / \mathrm{mg}$ protein).

The activity of caspase- 3 also depended on disease severity, similar to neutrophil apoptosis intensity. In particular, we found a reduction in its activity in newborns with severe pneumonia $(17.15$ (15.86; 18.75) $\mathrm{pmol} / \mathrm{mg}$ protein) compared with that of Group 1 (27.81 (24.99; 30.66) pmol/mg protein) (figure 3). A significant increase

Table 1. Statistical characteristics of nitric oxide (NO) indicators in newborns with pneumonia.

\begin{tabular}{|c|c|c|c|c|c|}
\hline \multirow[t]{3}{*}{ NO stable metabolites } & \multirow[t]{3}{*}{ Statistical indicators } & \multicolumn{4}{|c|}{ Groups of examined newborns } \\
\hline & & \multirow[t]{2}{*}{ Control group, $n=23$} & \multicolumn{3}{|c|}{ Newborns with pneumonia } \\
\hline & & & All (Gr. 1+Gr. 2), n=73 & Gr. $1, n=44$ & Gr. $2, n=29$ \\
\hline \multirow[t]{3}{*}{$\mathrm{NO} 2+\mathrm{NO} 3, \mu \mathrm{mol} / \mathrm{ml}$} & $\mathrm{Me}$ & 16.93 & 23.86 & $22.65^{*}$ & $26.82^{*}, * *$ \\
\hline & $\mathrm{Lq}$ & 15.82 & 22.35 & 21.42 & 25.81 \\
\hline & $\mathrm{Uq}$ & 17.79 & 25.96 & 23.40 & 27.91 \\
\hline \multirow[t]{3}{*}{$\mathrm{NO} 3, \mu \mathrm{mol} / \mathrm{ml}$} & $\mathrm{Me}$ & 15.96 & 20.56 & $19.46^{*}$ & $22.37^{\star}, * *$ \\
\hline & $\mathrm{Lq}$ & 15.13 & 19.24 & 18.39 & 21.89 \\
\hline & $\mathrm{Uq}$ & 16.84 & 21.96 & 20.31 & 23.12 \\
\hline \multirow[t]{3}{*}{$\mathrm{NO} 2, \mu \mathrm{mol} / \mathrm{ml}$} & $\mathrm{Me}$ & 0.75 & 3.34 & $3.06^{*}$ & $4.21^{\star}, * *$ \\
\hline & $\mathrm{Lq}$ & 0.65 & 3.01 & 2.89 & 3.95 \\
\hline & $\mathrm{Uq}$ & 0.95 & 4.01 & 3.25 & 4.57 \\
\hline \multirow[t]{3}{*}{ Percentage of NO2, \% } & $\mathrm{Me}$ & 4.73 & 14.49 & $13.82^{*}$ & $15.48^{*}, * *$ \\
\hline & $\mathrm{Lq}$ & 3.98 & 13.56 & 12.57 & 15.23 \\
\hline & $\mathrm{Uq}$ & 5.50 & 15.40 & 14.47 & 16.32 \\
\hline
\end{tabular}

Note: ${ }^{*}$ - significant difference compared with the control group $(\mathrm{p}<0.01)$

** - significant difference between Groups' 1 and 2 indexes $(\mathrm{p}<0.01)$ 
Table 2. Statistical characteristics of multiple and pairwise comparisons of nitric oxide (NO) indicators in newborns with pneumonia.

\begin{tabular}{lllll}
\hline $\begin{array}{l}\text { Statistical criteria of com- } \\
\text { parison and their level of } \\
\text { significance }\end{array}$ & NO indicators & & & \\
\cline { 2 - 5 } & $\mathrm{NO} 2+\mathrm{NO}, \mu \mathrm{mol} / \mathrm{ml}$ & $\mathrm{NO} 3, \mu \mathrm{mol} / \mathrm{ml}$ & $\mathrm{NO} 2, \mu \mathrm{mol} / \mathrm{ml}$ & Percentage of NO2, $\%$ \\
\hline $\mathrm{KW} \quad \mathrm{H}$ & 81.94 & 81.60 & 81.90 & 76.22 \\
\hline $\mathrm{y}$ & $<0.001$ & $<0.001$ & $<0.001$ & $<0.001$ \\
\hline $\mathrm{pW}$ & $\mathrm{U}(\mathrm{c}-1)=0.000$ & $\mathrm{U}(\mathrm{c}-1)=4.000$ & $\mathrm{U}(\mathrm{c}-1)=0.000$ & $\mathrm{U}(\mathrm{c}-1)=0.000$ \\
& $\mathrm{U}(\mathrm{c}-2)=0.000$ & $\mathrm{U}(\mathrm{c}-2)=0.000$ & $\mathrm{U}(\mathrm{c}-2)=0.000$ & $\mathrm{U}(\mathrm{c}-2)=0.000$ \\
& $\mathrm{U}(1-2)=0.000$ & $\mathrm{U}(1-2)=0.000$ & $\mathrm{U}(1-2)=0.500$ & $\mathrm{U}(1-2)=64.000$ \\
\hline & $\mathrm{pc}-1<0.001$ & $\mathrm{pc}-1<0.001$ & $\mathrm{pc}-1<0.001$ & $\mathrm{pc}-1<0.001$ \\
& $\mathrm{pc}-2<0.001$ & $\mathrm{pc}-2<0.001$ & $\mathrm{pc}-2<0.001$ & $\mathrm{pc}-2<0.001$ \\
& $\mathrm{p} 1-2<0.001$ & $\mathrm{p} 1-2<0.001$ & $\mathrm{p} 1-2<0.001$ & $\mathrm{p} 1-2<0.001$ \\
\hline
\end{tabular}

Note: The level of statistical significance according to the Bonferroni amendment was elected as $\mathrm{p}<0.025$ for comparison of indicators with the control group.

H, Kruskal-Wallis Test statistic; KW, Kruskal-Wallis test; MW, Mann Whitney test; U, Mann-Whitney U test.

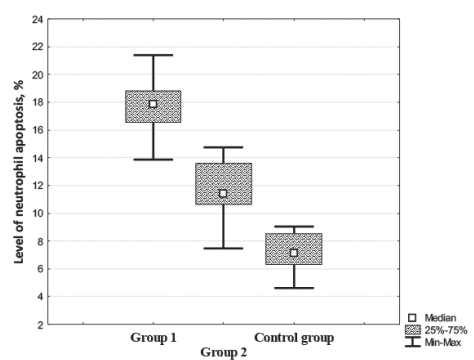

Figure 2. The serum level of neutrophil apoptosis (\% NA) in neonates with pneumonia and that of the control group.

in caspase- 3 activity in infants in Groups 1 and 2 compared to the control group was revealed using sequential comparison (pc-1<0.001, pc-2<0.001). A significant difference was determined using pairwise comparison between groups ( $\mathrm{p} 1-2<0.001)$. The level of neutrophil necrosis in newborns with pneumonia correlated with disease severity. In contrast to apoptosis, the intensity of neutrophil necrosis changed in another way. Thus, an increasing proportion of neutrophil apoptosis, as well as neutrophil necrosis, in neonates with pneumonia was found, but the necrosis of these immune cells statistically significantly increased with disease severity ( $\mathrm{p} 1$ $2<0.001)$. The level of necrotic neutrophils in infants in Group 1 was $0.96(0.75 ; 1.12)$ \%, in Group 2 - $1.93(1.73 ; 2.75) \%$, exceeding the control indicators $(0.27(0.18$; $0.32) \%$ ) by 3.6 and 7.1 times respectively (pc-1<0.001, pc-2<0.001) (figure 4).

Statistical variance analysis of the indicators of neutrophil apoptosis and necrosis in examined infants showed that results of Kruskal-Wallis test $(\mathrm{H})$ for all parameters was highly significant (H (neutrophil ap-

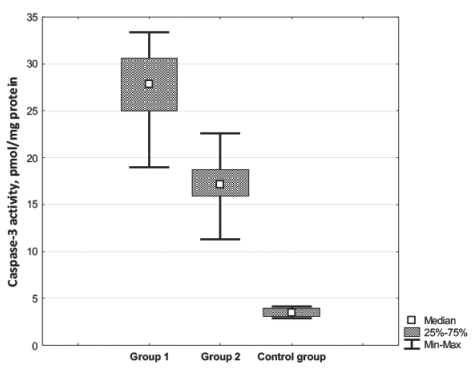

Figure 3. The level of caspase-3 activity in the blood serum of newborns with pneumonia and in the control group.

optosis) $=79.40, \mathrm{p}<0.001 ; \mathrm{H}$ (neutrophil necrosis) $=80.52, \mathrm{p}<0.001 ; \mathrm{H}$ (caspase -3 activity) $=80.20, \mathrm{p}<0.001$ ). This gives us the right to assert that the corresponding indicators of different groups are significantly different among themselves. These results can be confirmed by the high level of discrimination for: $\% \mathrm{NA}-\lambda=0.025055$, $\mathrm{F}=4.73, \mathrm{p}=<0.02 ; \% \mathrm{NN}-\lambda=0.060763$, $\mathrm{F}=76.31, \mathrm{p}<0.001$; and caspase- 3 activity $\lambda=0.046377, \mathrm{~F}=47.47, \mathrm{p}<0.001$.

Inverse correlations between nitric oxide indicators and levels of neutrophil apoptosis, and direct correlation between NO metabolites and neutrophil necrosis were found (table 3).

\section{DISCUSSION}

A moderate increase in the production of nitric oxide metabolites in newborns with pneumonia has a protective nature, aimed at the eradication of infectious agents. The antimicrobial action of $\mathrm{NO}$ is manifested by the ability of its reactive intermediate products to cause nitrosylation and deami-

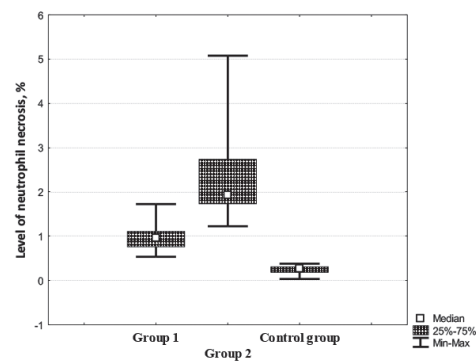

Figure 4. The level of neutrophil apoptosis $(\% \mathrm{NN})$ in the serum of neonates with pneumonia and in the control group.

nation of proteins, oxidative damage and breach of microorganisms' DNA repare system, blocking some of their enzymes and leading to their death. (11-13) The literature also shows the vasodilation effect of nitric oxide under hypoxic conditions that usually accompanies acute inflammation. $(14,15)$

However, excessive production of nitric oxide metabolites, that was observed in infants with severe pneumonia, has damaging effect, not only on bacteria, but also on the endothelium of lung blood vessels and immune cells, thereby increasing hypoxic changes and worsening the disease. Nitric oxide promotes severe vasodilatation, increases vascular permeability, thus leading to edema and further development of the inflammatory response. (16) It has also been proven that NO is involved in the suppression of immune responses. (17)

Thus, nitric oxide, as a mediator of inflammation, performs both regulatory and effector functions, showing protective or toxic effects depending on the concentration and stage of the immune response. On the one hand, NO is actively involved in 
the suppression and elimination of infectious microorganisms, while on the other, the excessive formation of this metabolite plays a prominent role in tissue damage, in toxic shock, in bacterial translocation and in multiple organ failure. $(3,12,13)$

Nitric oxide, not only participates in the non-specific defense of an organism, but also plays an important role in the regulation of cell death by apoptosis and necrosis. (18) It was shown that newborns with moderate pneumonia have an increased level of neutrophil apoptosis, which acts as a compensatory mechanism to diminish inflammation. Normally, after performing their protective antibacterial function, neutrophils undergo apoptosis, which preserves the integrity of the membranes and prevents the uncontrolled release of toxic contents of these cells in the environment. (19) The removal of apoptotic neutrophils by macrophages limits tissue damage in the resolution phase of inflammation, thus revealing the anti-inflammatory nature of apoptosis. (20) It has also been established that neutrophils, in the state of apoptosis, stop the production and the release of proinflammatory mediators. For this reason, the suppression of neutrophil apoptotic activity may be the cause of a prolonged and exacerbated inflammatory process in severe diseases. (21)

An increasing proportion of neutrophil apoptosis as well as neutrophil necrosis in neonates with pneumonia was found. Also, the necrosis of these immune cells was shown to increase significantly with disease severity. The intensity of neutrophil necrosis indicates increased inflammation and worsening of the disease state due to violation of cell membrane integrity, and the neutrophilic release of toxic materials in the extracellular space. It should be noted that the absence of an inflammatory response of neighboring cells to decay products, is an important feature of apoptosis that distinguishes it from necrosis. This is because cells in the state of apoptosis maintain membrane integrity up until the final stages of the process, and then undergo phagocytosis. Meanwhile, the infringement of cell membrane integrity due to necrosis, leads to lysosomal enzyme release, that enhances the development and progression of inflammation, which in turn aggravates the disease. $(19,22)$

The literature describes diametrically opposite effects of nitric oxide on programmed cell death. Nitric oxide metabolites may affect the viability of macrophages, neutrophils and other effector cells, by increasing or decreasing it. $(6,23)$ It was studied that excessive NO generation increases mitochondrial membrane potential and promotes cytochrome damage, which leads to caspase- 3 activation, inducing apoptosis. The damaging effect of nitric oxide on cellular DNA was found in vitro. (24)

At the same time, there are data about the antiapoptotic effects of nitric oxide. According to these studies, nitric oxide stabilizes caspase, preventing its activation and induces synthesis of anti-apoptotic proteins, (25) thus blocking their programmed cell death. Currently, the literature discusses the existence of self NOsignaling pathway for apoptosis. (24)
We have found an inverse correlation between NO indicators and the percentage of apoptotic neutrophils in newborns with pneumonia. This points to the inhibition of the neutrophil programmed cell death that is influenced by the overproduction of nitric oxide metabolites. Therefore, this leads to an increased intoxication state in the child's body due to the toxic accumulation of active neutrophils. At the same time, induction of neutrophil necrosis by products of $\mathrm{NO}$ metabolism, as evidenced by the direct correlation between the $\mathrm{NO}$ stable metabolites and necrotic neutrophils, increases the body's endogenous intoxication and complicates the disease. These results confirm the anti-apoptotic effect of nitric oxide, which is consistent with the scientific literature. Overproduction of NO metabolites inhibits proteinenzymes of the mitochondrial electron transport chain and Krebs cycle, and reduces adenosine triphosphate synthesis, that leads to necrosis. (26)

\section{CONCLUSIONS}

We have found increased generation of nitric oxide metabolites, that directly correlates with disease severity in newborns with pneumonia. Also, this study has proven that NO2has multidirectional effects on neutrophil apoptosis and necrosis, leading to toxic accumulation of neutrophils in the organism thus, enhancing the inflammatory and intoxication process that impacts on disease severity.

\section{REFERENCES}

1. Coleman JW. Nitric oxide in immunity and inflammation. Int Immunopharmacol 2001;1(8):1397-406.

2. Wallace JL. Nitric oxide as a regulator of inflammatory processes. Mem Inst Oswaldo Cruz 2005;100:5-9.

3. Tripathi P, Tripathi P, Kashyap L, Singh V. The role of nitric oxide in inflammatory reactions. FEMS Immunol Med Microbiol 2007;51(3):443-52.

4. Sharma JN, Al-Omran A, Parvathy SS. Role of nitric oxide in inflammatory diseases. Inflammopharmacology 2007,15(6):252-9.

5. Peranzoni E, Marigo I, Dolcetti L, Ugel S, Sonda N, Taschin E, et al. Role of arginine metabolism in immunity and immunopathology. Immunobiology 2007;212(9-10):795-812.

6. Bianchi SM, Dockrell DH, Renshaw SA, Sabroe I. Granulocyte apoptosis in the pathogenesis and resolution of lung disease. Clinical Science 2006;110 (3):293-304.

7. National guideline N 18 "Pediatric pulmonology" approved by Ministry of Health of Ukraine from 13.01.2005.

8. Looney MR, Matthay MA. Neutrophil sandwiches injure the microcirculation. Nat Med 2009;15(4):364-6.

9. Bonomini M, Dottori S, Amoroso A, Arduini A, Sirolli V. Increased platelet phosphatidylserine exposure and caspase activation in chronic uremia. J Thromb Haemost 2004;2(8):1-8.

10. Brabcova M, Rychlovsky P, Nemcova I. Determination of nitrites, nitrates, and their mixtures using flow injection analysis with spectrophotometric detection. Anal Lett 2003;36(10):2303-16.

11. Fang FC. Antimicrobial actions of nitric oxide. Nitric Oxide 2012;27(15):10-5.

12. Joerink M, Savelkoul HFJ, Wiegertjes GF. Evolutionary conservation of alternative activation of macrophages: structural and functional characterization of arginase 1 and 2 in carp (Cyprinus carpio L.) Mol Immunol 2006;43:1116-28.

13. Schairer DO, Chouake JS, Nosanchuk LD, Friedman AJ. The potential of nitric oxide releasing therapies as antimicrobial agents. Virulence 2012;3(3):271-9. 
14. Umbrella M, Dyson A, Feelisch M, Singer M. The key role of nitric oxide in hypoxia: hypoxic vasodilation and energy supply-demand matching. Antioxid Redox Signal 2013;19(14):1690-710.

15. Allen JD, Gow AJ. Nitrite, NO and hypoxic vasodilation. Br J Pharmacol 2009;158(7):1653-4.

16. Hauser B, Matejovic M, Radermacher P. Nitric oxide, leukocytes and microvascular permeability: causality or bystanders? Crit Care 2008;12:104-5.

17. Korhonen R, Lahti A, Kankaanranta H, Moilanen E. Nitric oxide production and signaling in inflammation. Curr Drug Targets 2005; 4(4):471-9.

18. Dal Secco D, Paron JA, de Oliveira SH, Ferreira SH, Silva JS, Cunha Fde Q. Neutrophil migration in inflammation: nitric oxide inhibits rolling, adhesion and induces apoptosis. Nitric Oxide 2003;9(3):153-64.

19. Fox S, Leitch AE, Duffin R, Haslett C, Rossi AG. Neutrophil apoptosis: relevance to the innate immune response and inflammatory disease. J Innate Immun 2010;2(3):216-27.

20. Rytila P, Plataki M, Bucchieri F, Uddin M, Nong G, Kinnula VL, et al. Airway neutrophilia in COPD is not associated with increased neutrophil survival. Eur Respir J 2006;28(6):1163-9.

21. Kebir DE, Filep JG. Role of neutrophil apoptosis in the resolution of inflammation. ScientificWorldJournal 2010;10:1731-48.

22. Rock KL, Kono H. The inflammatory response to cell death. Annu Rev Pathol 2008;3:99-126.

23. Stepovaya Y, Zhavoronok T, Starikov Y, BychkovY, Chasovskih N, Starikova Y. Regulatory Role of Nitric Oxide in Neutrophil Apoptosis. Bull Exp Biol Med 2008;146(6):737-40.

24. Dubey M, Nagarkoti S, Awasthi D, Singh AK, Chandra T, Kumaravelu J, et al. Nitric oxide-mediated apoptosis of neutrophils through caspase-8 and caspase-3-dependent mechanism. Cell Death Dis 2016;7, e2348; doi:10.1038/cddis.2016.248.

25. Hosking H. Nitric oxide and the immune system: a literature review. The Plymouth Student Scientist 2009;2(2):270-8.

26. Richardson AR, Payne EC, Younger N, Karlinsey JE, Thomas VC, Becker LA, et al. Multiple Targets of Nitric Oxide in the Tricarboxylic Acid (TCA) Cycle of Salmonella enterica Serovar Typhimurium. Cell Host Microbe 2011;10(1):33-43. 